\title{
Rethinking the Gap: Digital Preparedness and Social Inclusion of Young Generations in Remote Area to Lessen Digital Inequality
}

\author{
Nindi Aristi ${ }^{1 *}$ \\ ${ }^{1}$ Communication Studies Program, Faculty of Communication Sciences, Universitas Padjadjaran, West Java, Indonesia.
}

\begin{abstract}
The development of information and communication technologies (ICT) has changed many aspects of our lives around the world. ICT has played crucial roles in connecting people and places across regions and countries, also it helps global development more equally. It holds enormous promise for the future. In developed country like Indonesia the use of the digital advance to provide opportunities in economic and societal growth are vary, more chances in urban area than in remote area which is creating digital inequality. The young generations in Bengkulu province is having inequality of accessing and using the ICT, but the real problem is do they have the foundation to accept the ICT and does the social environment support for the changes? Case study method applied to understand the digital readiness of the young generations particularly the middle high school students and further to explore the social background as a way to minimizing the gap of digital inequality. Digital skills, trust, and use are the elements to measure the digital readiness. The result shows 1) the digital skills among the informants are still in basic level; 2) they depend on statement from friends and family in terms of trustworthiness; 3) they use the digital access mostly to chatting and watching YouTube. More affordable smartphone means more chance for the young generations to access the digital world but the social environment around them doesn't support evenly.
\end{abstract}

Keywords: digital inequality, digital divide, digital readiness. ict. social inclusion

\section{Introduction}

The development of information and communication technology is rising worldwide since 2002 when Internet was introduced to the world. The following years Internet has become integral part of our daily life and we are now the citizens of the digital era.

Indonesia as one of the developed countries in the world is contributing to the increasing number of Internet users. According to Wearesocial.org report in January 2017 the number of Internet users in Indonesia has reached 132.7 million users that is more than half of Indonesia's total population. It's predicted it will be increasing significantly in the years to come as info graphic shown below.

This positive change has brought some concerns regarding digital inequality in several provinces in Indonesia who cannot keep up with the digital transformation. Even though there is "Integrated Broadband Village (Desa Broadband Terpadu)" program from the Indonesian Ministry of Information and Communication which purpose to provide free Internet and digital infrastructure to people in remote areas throughout Indonesia regions, it doesn't mean the challenges of digital inequality are narrowing down. Because some places have difficult to reach such as environments and geographies.

In this paper we are focusing to Bengkulu Province that is still coping with the digital inequality problem and also is struggling with the poverty and social issues that need to be settled. In 2016 Bengkulu Province is named as the underdeveloped province in western region of Indonesia, in terms of digital development the local government has built 15 Internet free-access in eight districts but there are several issues need to be addressed in digital inequality.

In the past we can define the digital divide or digital inequality simply as binary division between information haves and have-nots but now we have to stretch the notion of a digital inequality to encompass broad array of social factors and resources. Mark Warschauer suggests alternative framework to look at digital divide is the intersection of ICT and social inclusion[1]. Social inclusion is a matter not only of an adequate share of resources but also participation in the determination of

* Corresponding author: nindi@unpad.ac.id 
both individual and collective life chances. There are many ways that the poor can have fuller participation and inclusion even if they lack an equal share of resources. The concept of social inclusion does not ignore the role of class but recognizes that a broad array of other variables help shape how class forces interact.

The digital inequality is a complex and dynamic issue that involves political and cultural dimensions. Some scholars accept the digital inequality as a natural phenomenon, therefore they don't suggest any intervention to bridge the digital inequality and the others have suggested adopting interventions. Before any intervention it's wise to comprehend the digital preparedness of the society we try to step in.

\section{Methodology}

In order to understand the digital inequality in Bengkulu Provinces concentrate on young generations dealing with the real problem in digital preparedness and social values background. We select 20 middle high school students to be our key informants in this research and deploy a series of in-depth interview to the key informants.

\section{Discussion}

In this section the aspects of digital preparedness of young generations in Bengkulu Province are explored using Pew Research Center framework that spread to three dimensions: digital skills, trust, and use. Digital skills are defined as the skills necessary to initiate an online session, surf the Internet and share content online. Jan van Dijk stated that digital skills as a crucial part of the appropriation of information and communication technology; it is the key to the information society[2].

Most of the middle high school students acclaimed they are having sufficient skills in using digital device mainly operating their smartphone. Ask if they are feeling confident in using smartphone, most of them said they are "very confident". Interestingly the reality was not the same as they claimed when we asked further about their knowledge of digital terms and how they handle technical problem on their smartphone.

They only knew few basic digital terms such as uploading, sign in, emoticon, download, follower, etc. They couldn't understand other digital terms such as algorithm, cookie, scamming, converting files, and other not so popular terms. It is understood their digital skills are still in the low level as they didn't get an appropriate digital education in school and limited financial resource from their parents to support them with extra training. Digital trust is people's belief about their capacity to determine the trustworthiness of information online and safeguard personal information. For measuring trust, the key informants were asked whether they face difficulties in finding reliable online information, 15 students said to be confused in identifying the incorrect information among others. They are used to accepting videos, photos, stories, and other information from social media such as WhattsApp, Line and Instagram and moreover they are sharing the information to their friends and family without double-checked if it's reliable or not.

In terms of personal information sharing to others via online, they are open and dare to put any detail about themselves without any worries of hacker, deceit, or other negative threat. When doing online transaction they are not so sure to trust based on online statement or testimony from friends and family in the decision making process. Digital use is the degree to which people use digital tools in the course of carrying out online tasks. In developed countries, computer use has become less a lifestyle option; it has more and more become an everyday necessity. Living without digital device is becoming increasingly difficult, as our key informants mentioned that they are hardly to be missed without their smartphone day in and day out. Most of the middle high school students are using their smartphone to chatting with their friends, discussing about the home assignment, and talking about games online. They would also spent some time watching Indonesia's artists video in YouTube and reading hot news in gossip channel such as Lambe Turah, approximately one to two hours a day. From the findings we can classify the digital preparedness of the key informants as the unprepared group based on the digital readiness spectrum in Figure 1.

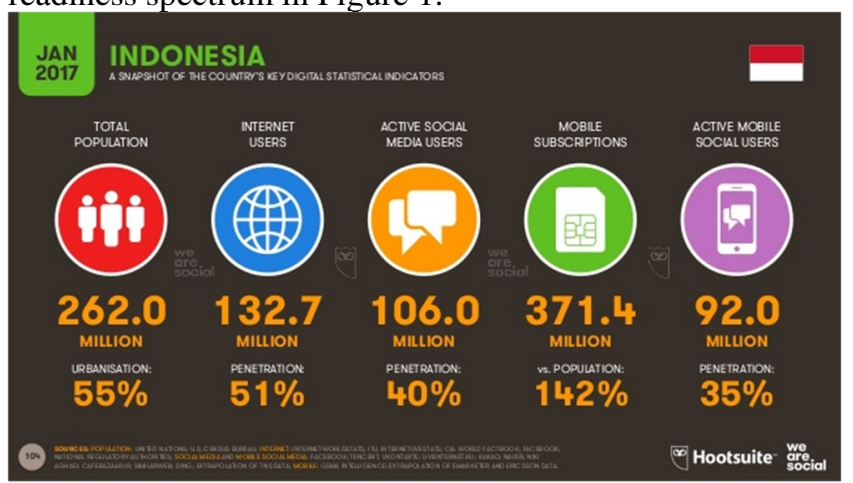

Figure 1. Internet users in Indonesia, 2017

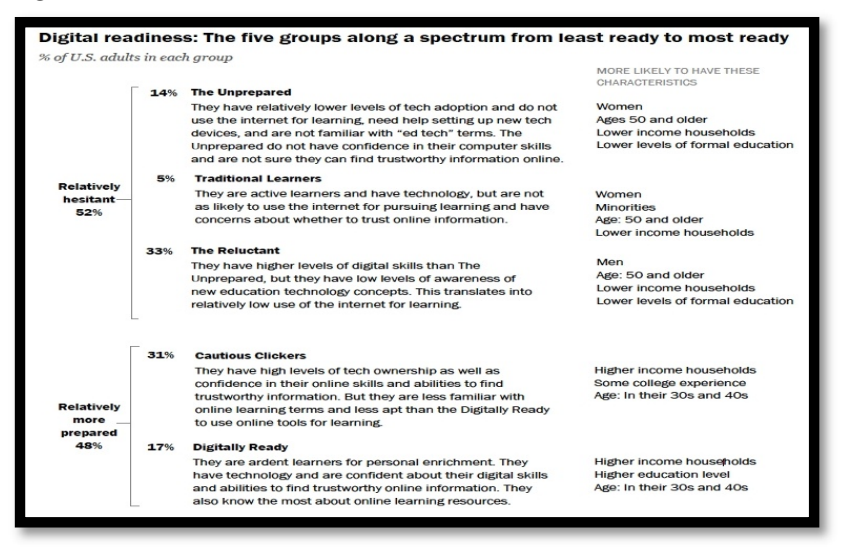

Figure 2. Digital Readiness Spectrum, Pew Research Center, 2015

To comprehend of the digital inequality condition in Bengkulu Province, we also make an effort to analyse the social inclusion aspect. Warschauer mentioned in his book, the social inclusion and exclusion are prominent concept in European discourse. They refer to the extent that individuals, families, and communities are able to fully participate in society and control their own destinies, 
taking into account a variety of factors related to economic resources, employment, health education, housing, recreation, culture, environment, and civic engagement.

Furthermore Stewart said social inclusion is a matter not only of an adequate share of resources but also of participation in the determination of both individual and collective life chances[3]. It seems there are opportunity that the poor can have fuller participation and inclusion even if they lack an equal share of resources. On 20162017 the sales of smartphone in Bengkulu Province was indicating rising demand of communication devices, there are many smartphone shops in the city centre. With affordable price everyone can buy smartphone and by owning smartphone, the key informants expect many things to look forward to.

The ICT development is also support from the government by providing the public access to Internet or free Internet access, although in Bengkulu province the Wi-Fi spot are still limited. The key informants are using the Wi-Fi spot frequently due to their limited money to reload their broadband package. Despite of limited access and communication device they can express their opinion through social media and make contribution on community and cultural activities. These are the form of social participation and everyone can take a part.

\section{Conclusion}

Exclusion from digital society is a serious problem therefore the young generations in Bengkulu Province are trying to get involved and interact with digital society freely. More affordable smartphone means more chance for the young generations to access the digital world but the social environment around them doesn't support evenly.

Although they are still being classified as the unprepared due to the low level of digital skills but that didn't stop them from sharing information online and using the smartphone device in their daily activities. They believe the more you get involved in digital society the more you minimize the digital inequality.

\section{References}

1. M, Warschaeur, Technology and Social Inclusion: Rethinking the digital divide", The MIT Press, London ( 2003).

2. J. A. G. M. Van Dijk, van Deursen, J.A.M. Alexander, Digital Skills: Unlocking the Information Society, New York, Palgrave Macmillan (2014).

3. A. Stewart, Social inclusion: An introduction, England, Macmillan (2000). 